\title{
SINTESIS BIODISEL MELALUI ESTERIFIKASI DAN TRANSESTERIFIKASI MINYAK NYAMPLUNG TEROZONISASI DENGAN BANTUAN GELOMBANG ULTRASONIK
}

\author{
(BIODIESEL SYNTHESIS THROUGH NYAMPLUNG OIL ESTERIFICATION \\ AND TRANSESTERIFICATION USING ULTRASONIC WAVES ASSIST)
}

\author{
Haryono, E. Evy Ernawati, Rukiah, dan Susi Suryani \\ Fakultas Matematika dan Ilmu Pengetahuan Alam Universitas Padjadjaran \\ Jl. Raya Bandung-Sumedang Km. 21 Jatinangor 45363 \\ e-mail: haryono_riyo@yahoo.com
}

\begin{abstract}
Abstrak
Tujuan penelitian ini adalah mensintesis biodiesel dari minyak nyamplung melalui proses esterifikasi dan transesterifikasi dengan bantuan ozonisasi dan gelombang ultrasonik. Ozonisasi dilakukan selama 30 menit, sedangkan reaksi transesterifikasi dibantu dengan gelombang ultrasonik pada variasi frekuensi 28 dan $35 \mathrm{kHz}$ masing-masing selama 30 menit. Hasil penelitian menunjukkan bahwa penggunaan gelombang ultrasonik dengan frekuensi $35 \mathrm{kHz}$ pada reaksi transesterifikasi terhadap minyak nyamplung terozonisasi dari reaksi esterifikasi dihasilkan biodiesel yang relatif sesuai dengan standar biodiesel Indonesia. Biodiesel yang dihasilkan pada kondisi tersebut memiliki bilangan asam 0,70 $\mathrm{mgKOH} / \mathrm{g}$ biodiesel, bilangan iodium $50,34 \mathrm{~g} \mathrm{I} / 100 \mathrm{~g}$, titik nyala $122,4^{\circ} \mathrm{C}$, bilangan cetana 102,5 , densitas $0,9088 \mathrm{~g} / \mathrm{cm}^{3}$, dan viskositas $9,5 \mathrm{cSt}$.

Kata kunci: biodiesel, minyak nyamplung, ozonisasi, transesterifikasi, ultrasonik
\end{abstract}

\begin{abstract}
This study was aimed at synthesizing biodiesel of nyamplung oil through esterification and transesterification process using ozonation and ultrasonic waves assist. The ozonation was done for 30 minutes, while the transesterification reaction was aided by ultrasonic wave frequency variation 28 and $35 \mathrm{kHz}$ for 30 minutes. The results show that the use of ultrasonic waves in frequency of $35 \mathrm{kHz}$ in the transesterification reaction to the ozonized nyamplung oil from esterification reaction produced biodiesel on the standards of Indonesian biodiesel. The biodiesel product in this study has $0.70 \mathrm{mgKOH} / \mathrm{g}$ biodiesel

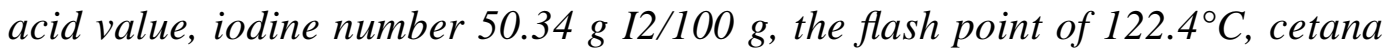
numbers of 102.5, density of $0.9088 \mathrm{~g} / \mathrm{cm} 3$, and a viscosity of $9.5 \mathrm{cSt}$.
\end{abstract}

Keywords: biodiesel, Calophyllum inophyllumoil, ozonation, transesterification, ultrasonic 


\section{PENDAHULUAN}

BPPT menyatakan bahwa konsumsi energi final di Indonesia pada periode 2000-2012 meningkat rata-rata sekitar $2,9 \%$ per tahun dengan konsumsi energi dominan berupa bahan bakar minyak seperti bensin, minyak diesel, minyak tanah, dan minyak bakar (BPPT, 2014). Lambat laun ketersediaan sumber energi ini akan terus menipis sehingga dibutuhkan suatu sumber energi terbarukan yang ketersediaannya dapat terus dipasok dan bersifat ramah lingkungan, misalnya biodiesel.

Jenis tanaman yang dapat digunakan sebagai bahan baku biodiesel antara lain minyak sawit (palm oil), minyak kelapa (coconut oil), minyak jarak pagar (Jatropha curcas oil), minyak biji kapok randu (Ceiba pantandra oil), dan minyak nyamplung (Gerpen, Shanks, Pruszko, Clements, \& Knothe, 2004). Minyak nyamplung dapat diperoleh dari biji nyamplung dengan kadar relatif tinggi yaitu sekitar 40-73\% dan tidak berkompetisi dengan minyak pangan. Selain itu, tanaman nyamplung sudah banyak tersebar di Indonesia (Hadi, 2009). Secara konvensional, biodiesel diproduksi melalui reaksi transesterifikasi dengan katalis basa homogen, seperti $\mathrm{NaOH}$ atau $\mathrm{KOH}$ pada suhu $65^{\circ} \mathrm{C}$ selama sekitar 60 menit (Garpen et al., 2004). Waktu reaksi sintesis biodiesel tersebut dapat direduksi dengan memperpendek molekul minyak bahan baku dan mengefektifkan kontak antarreaktan. Molekul minyak dapat diperpendek dengan ozonisasi. Penggunaan gelombang ultrasonik pada pembuatan biodiesel dapat mempersingkat waktu dari 1-6 jam menjadi kurang dari 60 menit, dan mempersingkat waktu pemisahan yang sebelumnya 5-8 jam menjadi kurang dari 60 menit (Bulent, 2008). Penelitian ini bertujuan untuk menghasilkan biodiesel dari minyak nyamplung yang telah diozonisasi melalui reaksi esterifikasi dan transesterifikasi dengan bantuan gelombang ultrasonik pada frekuensi dan lama reaksi yang divariasikan.

\section{METODE PENELITIAN}

Alat yang digunakan dalam penelitian ini antara lain peralatan gelas, piknometer, viskometer Oswald, timbangan analitis, Pensky-Marteen cup, dan GC-MS. Bahan yang digunakan antara lain minyak nyamplung, metanol, $\mathrm{NaOH}$, asam sulfat, $\mathrm{KI}$, amilum, dan asam asetat.

Metode yang digunakan dalam penelitian ini biodiesel diperoleh melalui 6 tahap proses, yaitu: degumming minyak nyamplung, ozonisasi minyak nyamplung, esterifikasi, pemurnian hasil esterifikasi, transesterifikasi dengan bantuan ultrasonik, pemurnian biodiesel, dan analisis biodiesel (analisis komposisi dan kualitas). Data-data pada penelitian ini berupa sifat-sifat fisik dan 
kimia dari minyak nyamplung sebelum dan setelah ozonisasi, setelah esterifikasi, dan setelah pemurnian produk transesterifikasi. Sifat fisika dan kimia yang dianalisis adalah densitas, viskositas, bilangan asam, bilangan iodium, bilangan penyabunan, titik nyala, bilangan cetana, dan komposisi kimia. Densitas dari minyak nyamplung dan biodiesel diukur dengan prinsip gravimetri menggunakan piknometer, sedangkan viskositas diukur berdasarkan waktu alir dengan viskometer Ostwald. Bilangan asam, penyabunan, dan iodium ditentukan dengan metode analisis volumetrik atau titrimetri. Titik nyala (flash point) biodiesel ditentukan dengan alat Pensky-Marteen cup tertutup. Sedangkan komposisi kimia dari minyak nyamplung dan biodiesel dianalisis dengan metode GCMS (Gas chromatography-mass spectrometry).

\section{HASIL DAN PEMBAHASAN}

Pada penelitian ini, hasil-hasil penelitian dalam bentuk penampilan fisik maupun hasil

analisis kimia diinspeksi pada tahap-tahap proses utama, yaitu: degumming, ozonisasi, esterifikasi, dan transesterifikasi.

Proses degumming terhadap minyak nyamplung dimaksudkan untuk meminimalkan kandungan gum/getah berupa senyawa fosfolipid dan fosfatida dalam minyak nyamplung. Perbandingan penampilan fisik antara minyak nyamplung sebelum dan setelah degumming ditampilkan pada Gambar 1, sedangkan hasil analisis sifat fisika dan komposisi kimianya ditampilkan pada Tabel 1 dan Tabel 2.

Gambar 1. Minyak Nyamplung Sebelum dan Setelah Degumming

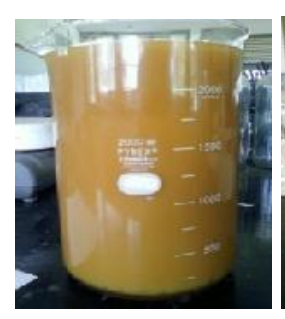

Sebelum

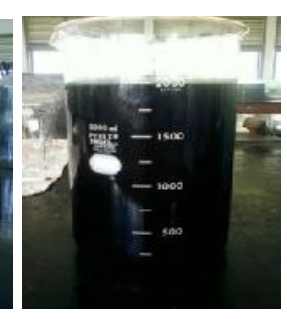

Setelah

Tabel 1

Hasil Analisis Minyak Nyamplung setelah Degumming

\begin{tabular}{clcc}
\hline No & \multicolumn{1}{c}{ Parameter } & Satuan & Nilai \\
\hline 1 & Bilangan asam & $\mathrm{mg} \mathrm{KOH} / \mathrm{g}$ & 47,44 \\
2 & Bilangan penyabunan & $\mathrm{mg} \mathrm{KOH} / \mathrm{g}$ & 139,08 \\
3 & Bilangan iodium & $\mathrm{g} \mathrm{I}_{2} / 100 \mathrm{~g}$ & 51,33 \\
4 & Densitas & $\mathrm{g} / \mathrm{cm}^{3}$ & 0,943 \\
5 & Viskositas & $\mathrm{cSt}$ & 56 \\
6 & Titik nyala & ${ }^{\circ} \mathrm{C}$ & 199,6 \\
\hline
\end{tabular}


Tabel 2

Jenis dan Komposisi Asam Lemak Minyak Nyamplung (Hasil Analisis dengan GCMS)

\begin{tabular}{clcc}
\hline No & Jenis Asam Lemak & Rumus Ikatan & Kadar $(\%)$ \\
\hline 1 & Asam palmitat & C16:0 & 0,38 \\
2 & Asam stearat & C18:0 & 15,67 \\
3 & Asam oleat & C18:1 & 40,41 \\
4 & Asam arachidat & C20:0 & 27,38 \\
5 & Asam eicosenoat & C20:1 & 0,19 \\
6 & Asam Heneicosanoat & C21:0 & 0,21 \\
7 & Asam benehat & C22:0 & 0,23 \\
\hline
\end{tabular}

Pada Gambar 1 tampak bahwa setelah proses degumming penampilan minyak nyamplung yang semula hijau tua pekat menjadi kuning-coklat cerah. Semakin cerahnya penampilan warna minyak nyamplung mengindikasikan bahwa sebagian besar bahan-bahan seperti gum dan khlorofil dalam minyak nyamplung telah berhasil dipisahkan.

Tabel 1 menunjukkan bahwa minyak nyamplung memiliki kandungan asam lemak bebas yang tinggi (lebih dari $2 \%$-b atau 4,0 $\mathrm{mg} \mathrm{KOH} / \mathrm{g}$ ). Viskositas yang tinggi dan bilangan iodium yang rendah menunjukkan bahwa minyak nyamplung didominasi oleh asam lemak jenuh rantai panjang. Hal tersebut dipertegas oleh hasil analisis jenis dan komposisi asam lemak seperti ditampilkan pada Tabel 2 .

Tahap ozonisasi dilakukan dengan maksud untuk lebih memperpendek ikatan karbon dari molekul minyak nyamplung melalui pemotongan ikatan rangkap (Zahardis \& Petrucci, 2007). Pada penelitian ini, keberhasilan ozonisasi didasarkan pada indikator naiknya bilangan asam dan penyabunan, serta turunnya bilangan iodium. Tabel 3 menampilkan hasil analisis minyak nyamplung setelah ozonisasi.

Perbandingan data pada Tabel 1 dan 3 menunjukkan, setelah ozonisasi, bilangan asam minyak nyamplung meningkat dari

Tabel 3

\begin{tabular}{clcc}
\multicolumn{4}{c}{ Hasil Analisis Minyak Nyamplung setelah Tahap Ozonisasi } \\
\hline No & \multicolumn{1}{c}{ Parameter } & Satuan & Nilai \\
\hline 1 & Bilangan asam & $\mathrm{mg} \mathrm{KOH} / \mathrm{g}$ & 50,24 \\
2 & Bilangan penyabunan & $\mathrm{mg} \mathrm{KOH} / \mathrm{g}$ & 143,74 \\
3 & Bilangan iodium & $\mathrm{g} \mathrm{I}_{2} / 100 \mathrm{~g}$ & 50,34 \\
\hline
\end{tabular}


47,44 menjadi 50,24 mg KOH/g minyak. Peningkatan bilangan asam tersebut timbul sebagai akibat terputusnya beberapa ikatan rangkap pada struktur molekul trigliserida minyak nyamplung menjadi asam lemakasam lemak bebasnya, sehingga diperlukan lebih banyak $\mathrm{KOH}$ untuk menetralkan asam lemak-asam lemak tersebut (Apriyantono, Fardiaz, Puspitasari, Sedarnawati, \& Budiyanto, 1989). Terputusnya ikatan rangkap pada minyak, juga berdampak pada turunnya ikatan tak jenuh yang ditunjukkan dengan menurunnya bilangan iodium menjadi $50,34 \mathrm{~g} \mathrm{I}_{2} / 100 \mathrm{~g}$ dari semula $51,33 \mathrm{~g} \mathrm{I}_{2} / 100 \mathrm{~g}$. Tahap esterifikasi dilakukan untuk mengkonversi asam lemak bebas dalam minyak menjadi metil ester sehingga tidak mengganggu pada tahap transesterifikasi (Knothe, Gerpen, \& Krahl, 2005). Langkah ini dilakukan karena pada tahap transesterifikasi digunakan $\mathrm{NaOH}$ sebagai katalis yang merupakan katalis basa homogen. Tahap esterifikasi yang dilakukan berhasil mengkonversi asam lemak bebas dari minyak nyamplung. Hal tersebut ditunjukkan penurunan bilangan asam dari 50,24 menjadi 8,43 dan 8,11 mg KOH/g masing-masing ketika digunakan gelombang ultrasonik berfrekuensi 28 dan $35 \mathrm{kHz}$.

Transesterifikasi dilakukan selama 30 menit pada suhu $65^{\circ} \mathrm{C}$ dengan rasio mol minyak/metanol sebesar 1:12 dan katalis $\mathrm{NaOH}$ sebanyak 2\%-b. Selama transesterifikasi dibantu dengan gelombang ultrasonik pada frekuensi divariasikan sebesar 28 dan $35 \mathrm{kHz}$. Hasil analisis mutu terhadap biodiesel yang dihasilkan dengan 2 variasi frekuensi gelombang ultrasonik tersebut ditampilkan pada Gambar 2. Hasil analisis komposisi kimia ditunjukkan pada Tabel 4.

Gambar 2 menunjukkan bahwa penggunaan frekuensi gelombang ultrasonik dengan frekuensi lebih tinggi pada reaksi tranesterifikasi, dihasilkan biodiesel dengan mutu lebih baik, yaitu terjadinya penurunan bilangan asam, densitas, dan viskositas. Hasil tersebut sesuai dengan hasil penelitian serupa dengan bahan baku minyak biji kapuk (Haryono, Kusumah, \& Natanael, 2014). Selain parameter mutu tersebut, juga dilakukan penentuan titik nyala dan bilangan cetana terhadap biodiesel. Bilangan cetana (BC) ditentukan dengan pendekatan yang diusulkan oleh Azam, Waris, \& Nahar (2005) berdasarkan persamaan berikut:

$$
B C=46,3+5458 / B S-0,255 * B I
$$

dengan $\mathrm{BS}=$ bilangan sabun dan $\mathrm{BI}=$ bilangan iodium.

Hasil penentuan titik nyala dan bilangan cetana terhadap biodiesel pada kondisi terbaik masing-masing sebesar $122,4^{\circ} \mathrm{C}$ dan 102,5. Tabel 4 menampilkan hasil analisis komposisi metil ester dari biodiesel. Jenis dan kadar metil ester pada biodiesel yang dihasilkan relatif bersesuaian dengan 


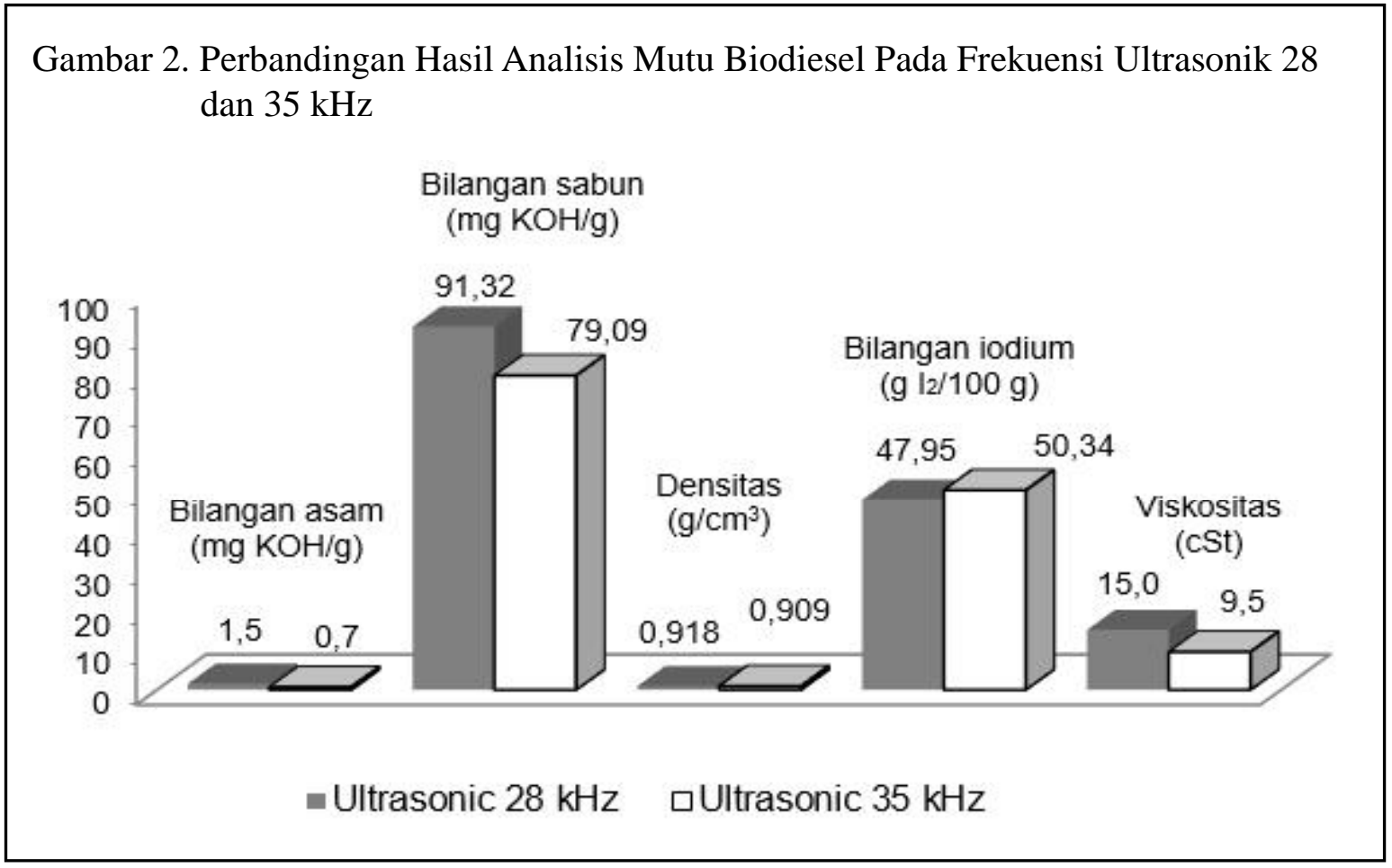

Tabel 4

Komposisi Metil Ester dari Biodiesel (Transesterifikasi pada Frekuensi Ultrasonik $35 \mathrm{kHz}$ )

\begin{tabular}{clcc}
\hline No & Jenis Metil Ester & Rumus Ikatan & Kadar (\%) \\
\hline 1 & Metil palmitat & C16:0 & 0,38 \\
2 & Metil stearat & C18:0 & 15,64 \\
3 & Metil oleat & C18:1 & 40,54 \\
4 & Metil arachidat & C20:0 & 27,33 \\
5 & Metil eicosenoat & C20:1 & 0,18 \\
6 & Metil Heneicosanoat & C21:0 & 0,03 \\
7 & Metil benehat & C22:0 & 0,21 \\
\hline
\end{tabular}

jenis dan kadar asam lemak dalam minyak nyamplung sebagai bahan baku seperti ditampilkan pada Tabel 2.

\section{SIMPULAN}

Hasil penelitian menunjukkan bahwa penggunaan gelombang ultrasonik dengan frekuensi $35 \mathrm{kHz}$ pada reaksi transesterifikasi terhadap minyak nyamplung terozonisasi dari reaksi esterifikasi dihasilkan biodiesel yang relatif sesuai dengan standar biodiesel Indonesia. Biodiesel yang dihasilkan pada kondisi tersebut memiliki bilangan asam $0,70 \mathrm{mgKOH} / \mathrm{g}$ biodiesel, bilangan iodium 
$50,34 \mathrm{~g} \mathrm{I}_{2} / 100 \mathrm{~g}$, titik nyala $122,4^{\circ} \mathrm{C}$, bilangan cetana 102,5, densitas $0,9088 \mathrm{~g} / \mathrm{cm}^{3}$, dan viskositas $9,5 \mathrm{cSt}$.

\section{DAFTAR PUSTAKA}

Azam, M. M., Waris, A., \& Nahar, N. M. (2005). Prospects and potential of fatty acid methyl esters of some nontraditional seed oils for use as biodiesel in India. J. Biomass \& Bioenergy, 29, 293-302.

Apriyantono, A., Fardiaz, D., Puspitasari, N. L., Sedarnawati, B. S., \& Budiyanto, S. (1989). Analisis pangan. Pusat Antar Universitas Pangan dan Gizi, IPB, Bogor.

BPPT [Badan Pengkajian dan Penerapan Teknologi]. (2014). Outlook energi Indonesia 2014: Pengembangan energi untuk mendukung program substitusi $B B M$. Jakarta.

Bulent, A. (2008). Ultrasonic monitoring of glycerol settling during transesterification of soybean oil. Bioresource Technology, 100, 19-24.

Garpen, V. J., Shanks, B., Pruszko, R., Clements, D., \& Knothe, G. (2004). Bio- diesel production technology. National Renewable Energy Laboratory. US Department of Energy, Colorado, USA.

Hadi, W. A. (2009). Pemanfaatan minyak biji nyamplung (Calophyllum inophyllum L.) sebagai bahan bakar minyak pengganti solar. Jurnal Riset Daerah, 8(2), 1044.

Haryono, Kusumah, H. W., \& Natanael, C. L. (2014, November). Biodiesel synthesis from cotton seed oil through ozonization and ultrasonication processes use calcium oxide catalyst from eggshell. Makalah dipresentasikan pada The $3^{\text {rd }}$ International Seminar on Chemistry 2014. Department of Chemistry, Universitas Padjadjaran, Bandung.

Knothe, G., Gerpen, J. V., Krahl, J. (2005). The biodiesel handbook. ChampaignIllinois: AOCS Press.

Zahardis, J., \& Petrucci, G. A. (2007). The oleic acid-ozone heterogeneous reaction system: Products, kinetics, secondary chemistry, and atmospheric implications of a model system. Atmos. Chem. Phys., 7, 1237-1274. 